\title{
Safety and efficacy of drugs: What do I need to know?
}

\section{Mahmoud Hadipour Dehshal}

\section{Charity Foundation for Special Diseases (CFSD), Tehran, Iran}

Access to the essential medicines is an important challenge in the developing countries. To have access to the quality and affordable medicines, the pharmaceutical decision makers try different strategies. The production of generic and copy medicines is one of the strategies that if adopted based on the recognized standards and norms can be effective in raising the health status in the developing countries. According to US Food and drug Administration, "a generic drug is a medication created to be the same as an already marketed brand-name drug in dosage form, safety, strength, route of administration, quality, performance characteristics, and intended use. These similarities help to demonstrate bioequivalence, which means that a generic medicine works in the same way and provides the same clinical benefit as its brand-name version". To make it more understandable, you can define a generic medicine as an equal substitute for its brand-name if it has been produced based on standard norms. However, shakable regulation impairs the qual- ity of generic and copy medicines and harms the health of consumers. NGOs including advocacy groups and scientific groups play effective and undeniable role to ensure quality of the health services which patients receive. Therefore, building a network between activists and scientists is the first step towards better quality. Since we are living in a global market and pharmaceutical active ingredients of pharmaceutical finished products can be found in different regions in the market, the second step of the battle against substandard is to make an international network between advocacy groups. The international network assists to prevent menaces of substandard medicines faster and with reliance on a scientific approach. Furthermore, in the lecture, we aim to reflect over the role of different beneficiaries including international organizations, governments, and pharmaceutical companies in ensuring the feasible and sustainable access of citizens to the essential medicines.
Correspondence: Mahmoud Hadipour Dehshal, Charity Foundation for Special Diseases (CFSD), Tehran, Iran

E-mail: Mehregan_hadipour@yahoo.com

This work is licensed under a Creative Commons Attribution 4.0 License (by-nc 4.0).

(C) Copyright M. Hadipour Dehshal, 2018

Licensee PAGEPress, Italy

Thalassemia Reports 2018; 8:7494

doi:10.4081/thal.2018.7494 